\title{
Ultrawide field imaging with navigable magnifier for diagnosis of diffuse unilateral subacute neuroretinitis
}

\author{
Gunjan Saluja, ${ }^{1}$ Hemant Kumar Joshi, ${ }^{1}$ Brijesh Takkar, ${ }^{1}$ Pradeep Venkatesh ${ }^{2}$
}

'Rajendra Prasad Centre for Ophthalmic Sciences, All India Institute of Medical Sciences, New Delhi, India

${ }^{2}$ Department of Ophthalmology, All India Institute of Medical Sciences, New Delhi, India

Correspondence to Dr Pradeep Venkatesh, venkyprao@yahoo.com

Accepted 28 November 2017

\section{DESCRIPTION}

A 52-year-old female presented with painless loss of vision in right eye since 3-4 years. Visual acuity was counting fingers close to face in right eye and 20/20 in left eye. Anterior segment examination and intraocular pressure were normal in both eyes. Right eye had multiple areas of pigment mottling and deep retinal scarring scattered throughout the fundus, along with optic disc atrophy (figure 1). Fundus examination of left eye was unremarkable. Window defects were detected on ultrawide field fluorescein angiography. Diffuse unilateral subacute neuroretinitis (DUSN) was suspected due to the ultrawide field imaging (UWFI) characteristics. The clinical UWFI was scanned with a navigable magnifier available in the software (Optos PLC, Dunfermline, UK). A slender, white-coloured, minimally curved structure was identified in the temporal pre-equatorial region with an adjoining scar (figure 2).

DUSN is a rare zoonosis, often diagnosed late and resulting in irreversible visual loss. Subretinal nematodes have been identified as its aetiology and their motion in the subretinal space is believed to result in the 'unilateral wipe-out' like findings. ${ }^{1}$ However, the parasite can be identified in only about one-third of the cases. The diagnosis is primarily clinical, and other investigations like angiography, electrophysiology, serology and optical coherence tomography are only ancillary. ${ }^{1-3}$ As the worm is known to be migratory and invades the peripheral retinal space frequently, meticulous assessment of the peripheral fundus is mandatory for localisation of the parasite in suspected cases. ${ }^{2}$ In this regard, UWFI proved to be a very useful tool for diagnosing DUSN in this case, which had presented very late.

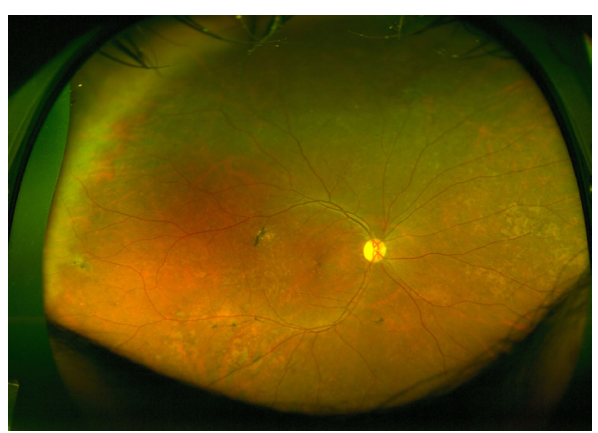

Figure 1 UWFI of the right eye depicting multiple areas of extensive pigment mottling scattered throughout the fundus along with deep retinal scarring in posterior as well as peripheral retina. Optic disc is pale suggesting optic atrophy. UWFI, ultrawide field imaging.

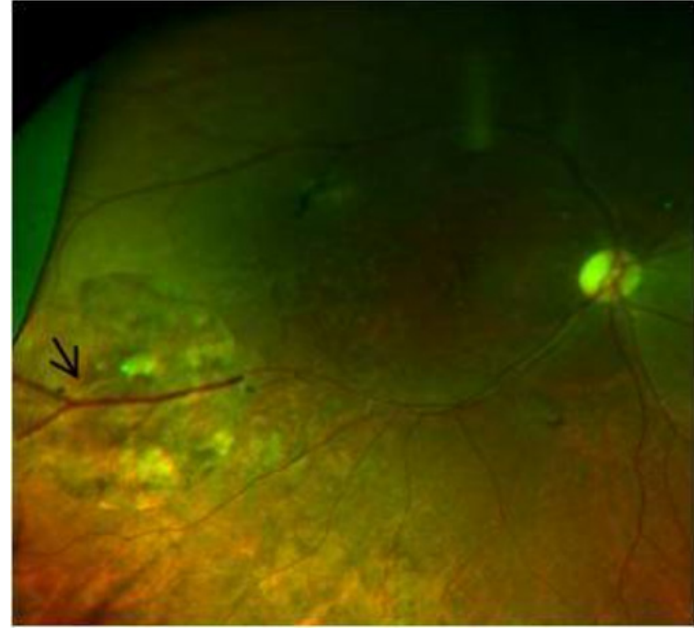

Figure 2 UWFI of right eye aided by integrated navigable magnifier. A slender white structure can be seen in temporal fundus (arrow) within the circular area magnified with the software. This structure is surrounded by scarred retina and pigmentary changes. UWFI, ultrawide field imaging.

The UWFI employed by us is based on a confocal scanning laser system that uses optics of an ellipsoid mirror to create a single image of up to $200^{\circ}$. The software includes a magnifying tool with a navigable magnifier that can be easily moved over the acquired images while allowing different levels of magnification. In our case, it helped in detecting a white structure similar to a dead worm or a subretinal tunnel (Garcia's signs) in the retinal periphery. $^{1}$

\section{Learning points}

- Diffuse unilateral subacute neuroretinitis may present late, and high index of suspicion should be maintained during clinical workup.

- Ultrawide field imaging, especially with the navigable magnifier, enables detection of the worm, which may otherwise be elusive on examination.

Contributors GS, HKJ, BT and PV worked up and diagnosed the patient. HKJ and BT performed imaging. GS and BT wrote the manuscript, and PV critically revised it. PV holds the overall responsibility.

Competing interests None declared.

Patient consent Obtained.

Provenance and peer review Not commissioned; externally peer reviewed. 
(c) BMJ Publishing Group Ltd (unless otherwise stated in the text of the article) 2017. All rights reserved. No commercial use is permitted unless otherwise expressly granted.

\section{REFERENCES}

1. Arevalo JF, Garcia RA, Tata LS, et al. Diffuse unilateral subretinal neuroretinitis (DUSN). Arévalo JF, ed. Retinal and Choroidal manifestations of selected systemic diseases. New York: Springer:23-35.
2. Venkatesh P, Sarkar S, Garg S. Diffuse unilateral subacute neuroretinitis: report of a case from the Indian subcontinent and the importance of immediate photocoagulation. Int Ophthalmol 2005;26:251-4.

3. Garcia Filho CA, Garcia CA, Arevalo JF. Imaging in the diagnosis and management of diffuse unilateral subacute neuroretinitis. Int Ophthalmol Clin 2012;52:283-9.

Copyright 2017 BMJ Publishing Group. All rights reserved. For permission to reuse any of this content visit http://group.bmj.com/group/rights-licensing/permissions.

BMJ Case Report Fellows may re-use this article for personal use and teaching without any further permission.

Become a Fellow of BMJ Case Reports today and you can:

- Submit as many cases as you like

- Enjoy fast sympathetic peer review and rapid publication of accepted articles

- Access all the published articles

- Re-use any of the published material for personal use and teaching without further permission

For information on Institutional Fellowships contact consortiasales@bmjgroup.com

Visit casereports.bmj.com for more articles like this and to become a Fellow 